\title{
The Effect of Graphene Coating on Surface Roughness and Friction Properties of Polyester Fabrics
}

\author{
Gizem MANASOGLU, Rumeysa CELEN*, Mine AKGUN, Mehmet KANIK
}

Bursa Uludag University, Textile Engineering Department, Bursa, Turkey

crossref http://dx.doi.org/10.5755/j02.ms.27903

Received 21 October 2020; accepted 11 January 2021

\begin{abstract}
In this article, the surface roughness and friction coefficient values of graphene coated fabrics were examined. Fabrics were coated with three different graphene concentrations (5\%, $10 \%$ and $20 \%$ ) with the knife-over-roll principle. The surface roughness of samples was measured by Accretech Surfcom 130A. Various surface roughness parameters of the coated fabrics were evaluated. Static and kinetic friction coefficients of coated fabrics were measured by Labthink Param MXD-02 friction tester using the standard wool abrasive cloth. It was observed that the coating concentration affected the frictional and roughness properties of fabrics. Experimental results showed that fabric surface roughness and friction coefficient values decreased significantly, especially at $20 \%$ concentration. It was concluded that the coated fabrics produced could be used in applications such as anti-wear clothing.

Keywords: surface roughness, friction coefficient, graphene, coating, polyester.
\end{abstract}

\section{INTRODUCTION}

Polymer-coated textiles are flexible composite materials comprising the coat (the polymer) and the substrate (textile layers) adhered together through a specific coating process to provide additional properties for the system [1]. Coated fabrics find an important place among technical textiles and are one of the most important technological processes in the modern industry [2]. Some of the polymer-coated textiles are used in aerospace, automotive (e.g., airbags), chemical processing, electronic, geotextile, military, filtration and heating, venting and air conditioning applications [1].

Graphene is a material that attracts attention in many areas such as electronics, composites, coatings, textiles, energy, etc. due to its superior properties. Sahito et al. studied about electrical properties of graphene coated cotton fabric [3]. Kongahge et al. coated the nonwoven polyester with liquid crystallite graphene oxide and electrical, mechanical, thermal and abrasion resistance properties were measured [4]. Celen et al. studied performance properties (abrasion resistance, tear strength, bursting strength, etc.) of graphene coated polyester woven fabrics [5]. ShateriKhalilabad et al. investigated the electrical conductivity and mechanical performance of graphene-coated cotton textiles [6]. Tas et al. produced graphene and graphene oxide-coated polyamide monofilament yarns for fiber-shaped flexible electrodes. The electrical and optical properties of monofilament yarns were measured [7].

Neves et al. produced graphene coated conductive fibers to use transparent and flexible electrodes [8]. Manasoglu et al. investigated the thermal conductivity and electrical resistivity of graphene coated polyester fabrics [9]. The surface properties of textile materials are essential for all textile products in many situations, from production to performance of the final product. Surface roughness and frictional properties often determine the useful performance of materials or objects [10]. Surface roughness is one key outcome of the coating process. In the context of coated fabrics, surface roughness serves as a measure of the variability in coating thickness at topographical features, including 'hills' and 'valleys' [11]. There are many studies on the roughness and frictional properties of textile materials [12-20]. However, there are limited studies on surface roughness and frictional properties of coated fabrics. Wan and Stylios studied the effects of coating process parameters such as curing temperature, gap spacing, coating speed and viscosity on the surface roughness of coated fabrics [11]. Bertaux et al. studied the frictional properties of plasma-coated fabrics. They established that the water repellence of the siloxane-coated fabrics had a positive effect on reducing friction coefficient under wet conditions [21]. Mostafa et al. studied the surface roughness properties of cotton fabrics treated with different concentrations of starch nanoparticles via coating technique using the paddry-cure method. The surface roughness values increased with increasing starch concentration [22].

In our previous studies, mechanical [5], thermal and electrical [9] properties of graphene coated fabrics were investigated. In addition to its functional properties, the surface properties of coated fabrics are also important. Besides the prominent thermal, mechanical and electrical properties of graphene, some studies [23 - 25] investigate its tribological properties and demonstrate its potential for use in micro-electromechanical systems (MEMS), anti-wear coating applications etc. due to its low friction coefficient. In these studies, mostly graphene derivatives (such as graphene oxide) were applied to metal, silicon, etc. surfaces, and generally spray coating and solution coating techniques were used. However, no studies are investigating the surface properties of graphene coating in textile applications. For

\footnotetext{
* Corresponding author. Tel.: +90-224-2942036; fax: +90-224- 2941903

E-mail address: rumeysa@uludag.edu.tr (R. Celen)
} 
this purpose, the surface roughness and frictional properties of polyester fabrics coated with graphene by knife-over-roll coating were evaluated for the first time.

The coating process was performed according to the knife-over-roll method at different graphene concentration rates. The coating concentration rates affected the surface roughness and frictional properties of fabrics in different manners.

\section{EXPERIMENTAL}

\subsection{Materials}

Pre-treated polyester plain weave fabric which was desized and thermofixed by the supplier (DKC Technical Coating Company) was used in the experiments. The structural properties of fabric were given in Table 1. Graphene powder which was supplied by the Grafen Chemical Industries was used as filler material and its properties were given in Table 2 . The coating chemicals such as a binder, thickener, fixation agent, anti-foam agent, dispergator were supplied from Rudolf Duraner (Bursa) and their properties are given in Table 3.

Table 1. Structural properties of polyester fabric

\begin{tabular}{|c|c|c|}
\hline Property & Warp & Weft \\
\hline Yarn type & \multicolumn{2}{|c|}{ Texturized polyester } \\
\hline Yarn count, tex & \multicolumn{2}{|c|}{33} \\
\hline Yarn density, thread/cm & 30 & 18 \\
\hline Yarn crimp, \% [ASTM D3883-04] & 1.16 & 0.30 \\
\hline
\end{tabular}

Table 2. Properties of graphene

\begin{tabular}{|c|c|}
\hline Property & Value \\
\hline Purity, $\%$ & $96-99$ \\
\hline Surface area, $\mathrm{m}^{2} / \mathrm{g}$ & $13-15$ \\
\hline Thickness, $\mathrm{nm}$ & $50-100$ \\
\hline Diameter, $\mu \mathrm{m}$ & $\sim 5$ \\
\hline
\end{tabular}

Table 3. Properties of coating chemicals

\begin{tabular}{|l|l|}
\hline Chemical & \multicolumn{1}{|c|}{ Property } \\
\hline Binder & Acrylic binder, anionic/nonionic \\
\hline Fixation agent & $\begin{array}{l}\text { The butanone oxime-free blocked } \\
\text { isocyanate-based crosslinking agent, } \\
\text { anionic }\end{array}$ \\
\hline Synthetic thickener & Neutralized polyacrylate, anionic \\
\hline Anti-foam agent & $\begin{array}{l}\text { Hydrocarbons, ethoxylated fatty acids } \\
\text { and silicic acid combination, nonionic }\end{array}$ \\
\hline Ammonia & 25\% liquid \\
\hline
\end{tabular}

\subsection{Methods}

\subsubsection{Coating process}

In the first stage, coating pastes were prepared at three different concentration rates (5\%, $10 \%$ and $20 \%$ ) with graphene nano-powder. Coatings were performed according to the knife-over-roll principle on a laboratory type coating machine (ATAÇ GK40 RKL, Fig. 1). In the second stage, the curing process in which cross-linking accrued was performed on Rapid HT Steamer at a constant temperature. The detailed process parameters are given in Table 4 .

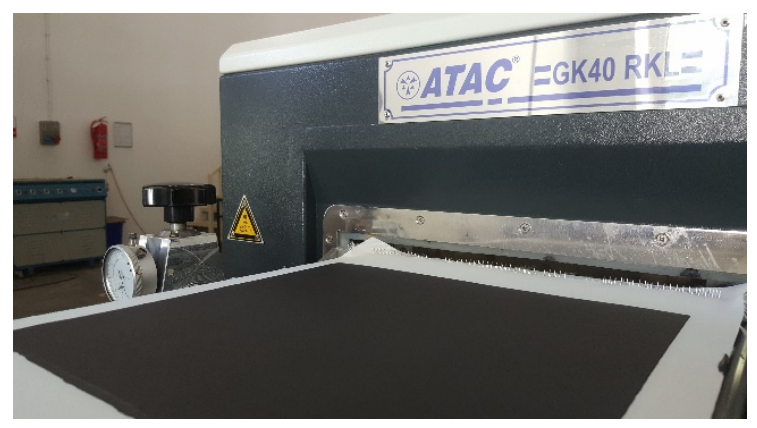

Fig. 1. Graphene coated fabric sample

Table 4. Coating process parameters

\begin{tabular}{|c|c|}
\hline Parameter & Values \\
\hline Drying temperature/period & $100^{\circ} \mathrm{C} / 10 \mathrm{~min}$ \\
\hline Curing temperature/period & $160^{\circ} \mathrm{C} / 3 \mathrm{~min}$ \\
\hline Knife gap & $0.5 \mathrm{~mm}$ \\
\hline
\end{tabular}

\subsubsection{Measurements of fabric thickness and fabric mass per unit area}

Thickness measurements of coated fabrics were made according to TS 7128 EN ISO 5084 Standard with James Heal's R \& B Cloth thickness tester. Three measurements were taken for each fabric and the average thickness values of the fabrics were calculated.

The measurement of the mass per unit area was carried out by the TS 251 standard. Each sample was weighed three times on a precision scale and the average value was calculated.

\subsubsection{Microscopic analyses}

SEM images of uncoated and coated fabrics were taken with Zeiss EVO 40 scanning electron microscope. Magnification rates were chosen as $100^{\mathrm{X}}$ and $500^{\mathrm{X}}$.

\subsubsection{Measurement of surface roughness}

The surface roughness of samples was measured by a roughness tester (Accretech Surfcom 130A) and surface roughness values were recorded according to ISO 4287-1997. The arithmetic average height $\left(R_{\mathrm{a}}\right)$ parameter gives a general definition of the height variation of surfaces. Arithmetic average height $\left(R_{\mathrm{a}}\right)$ is defined as the average absolute deviation of the roughness irregularities from the mean line over one sampling length. The mean height of peaks values $\left(R_{\mathrm{pm}}\right)$ is defined as the mean of the maximum height of peaks $\left(R_{\mathrm{p}}\right)$ obtained for each sampling length of the assessment length. The mean depth of valleys $\left(R_{\mathrm{vm}}\right)$ is defined as the mean of the maximum depth of valleys $\left(R_{\mathrm{v}}\right)$ obtained for each sampling length of the assessment length. Skewness $\left(R_{\mathrm{sk}}\right)$ of a profile is the third central moment of profile amplitude probability density function, measured over the assessment length [26, 27].

Evaluation length and evaluation speed were chosen as $50 \mathrm{~mm}$ and $1.5 \mathrm{~mm} / \mathrm{s}$, respectively. The surface roughness was measured in both the warp and weft directions. Three measurements were taken for each fabric and the average roughness values of the fabrics were calculated.

\subsubsection{Surface friction measurement}

Static and kinetic friction coefficients of coated fabrics were measured by Labthink Param MXD-02 friction tester 
according to ASTM D 1894. Friction coefficients of the samples were measured by fabric-to-fabric friction using plain weave standard abrasive wool cloth (ASTM D 4966) which has $16 \mu \mathrm{m}$ surface roughness value. The abrasive fabric under test was mounted on the sled (mass of sled: 200 g) and the coated fabric was mounted on the moving plate (test speed: $150 \mathrm{~mm} / \mathrm{min}$; stroke $150 \mathrm{~mm}$ ) of the coefficient tester. Friction measurements were performed in the warp and weft direction of fabric samples under test. Three measurements were recorded and the mean was calculated.

\section{RESULTS AND DISCUSSION}

\subsection{Fabric thickness and mass per unit area results}

Mass per unit area and thickness measurement results of the fabrics coated with graphene at three different concentrations (5\%, $10 \%$ and $20 \%$ ) are given in Table 5.

Table 5. Thickness and mass per unit area results

\begin{tabular}{|c|c|c|c|}
\hline $\begin{array}{c}\text { Sample } \\
\text { code }\end{array}$ & $\begin{array}{c}\text { Concentration, } \\
\mathrm{g} / \mathrm{kg}\end{array}$ & $\begin{array}{c}\text { Mass per unit } \\
\text { area, } \mathrm{g} / \mathrm{m}^{2}\end{array}$ & $\begin{array}{c}\text { Fabric thickness, } \\
\mathrm{mm}\end{array}$ \\
\hline Uncoated & 0 & 169 & 0.34 \\
\hline GR50 & 50 & 292.16 & 0.39 \\
\hline GR100 & 100 & 324.16 & 0.41 \\
\hline GR200 & 200 & 377 & 0.48 \\
\hline
\end{tabular}

Coated fabrics were coded according to graphene concentration as GR50, GR100 and GR200, respectively. Fabric mass per unit area and thickness values increased with the increasing graphene concentration (the solid content ratio in the coating paste) as expected.
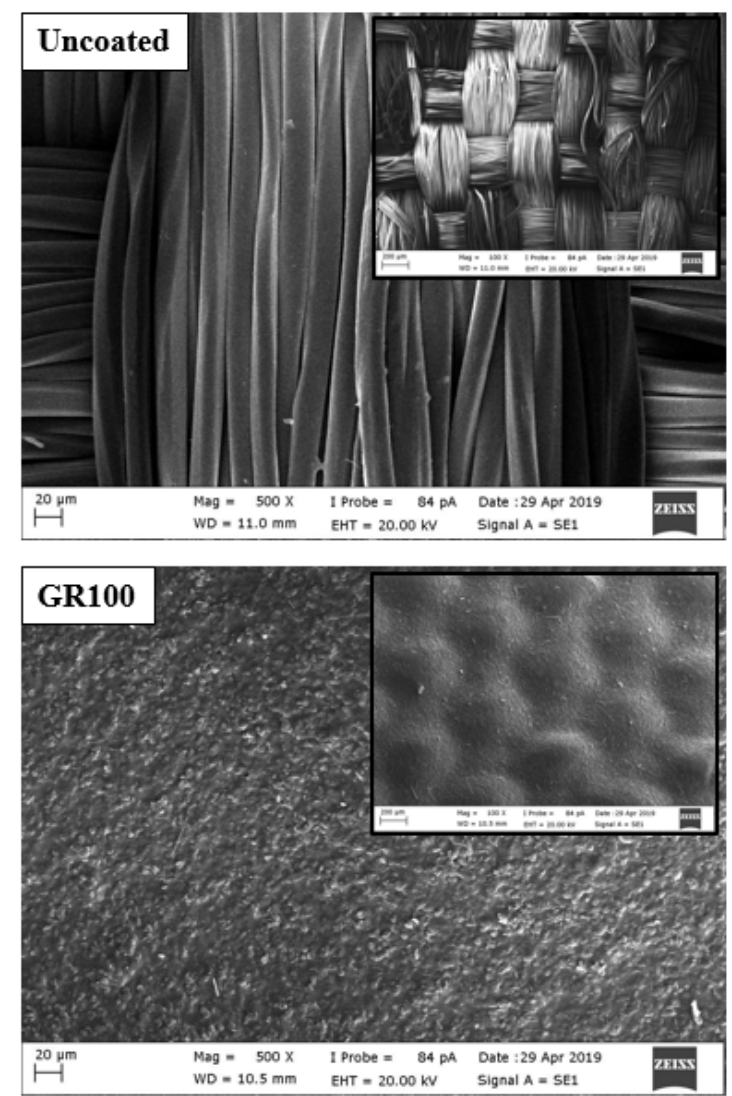

\subsection{Microscopic analysis results}

SEM images of uncoated and coated fabrics are shown in Fig. 2. The $100^{\mathrm{X}}$ images are placed on the upper right of $500^{\mathrm{X}}$ images. The images showed that the coating process was carried out successfully and the surfaces obtained were homogeneous. SEM images confirmed that the coverage of the coating surface was increased with the increasing concentration of graphene. SEM images of the GR 50 and GR100 coded fabrics were closer to each other than the GR 200 coded fabric surface. It can be said that $5 \%$ and $10 \%$ concentration had a similar effect on the rate of filling the gaps between the peak and the valley at the intersection points of the fabric. This was confirmed by the fact that the thickness values of GR50 and GR100 coded fabrics were also close to each other. The difference between the heights of yarn peaks on the surface decreased significantly at $20 \%$ concentration. As a result of this, the thickness value of GR200 coded fabrics increased significantly.

\subsection{Assessment of surface roughness of coated fabrics}

Changes in the arithmetic average height $\left(R_{\mathrm{a}}\right)$ values are given in Fig. 3 to evaluate the coating concentration's effect on the surface roughness of the fabrics. Fig. 3 shows that the fabric surface roughness values decreased significantly after the coating process. The high surface roughness value obtained from the uncoated fabric was due to the height distribution variations between the yarn crown peaks and gaps resulting from the intersection of the yarns on the fabric surface, as seen in Fig. 2. This is due to the increase in mechanical intersection heights of the yarn crowns [28].
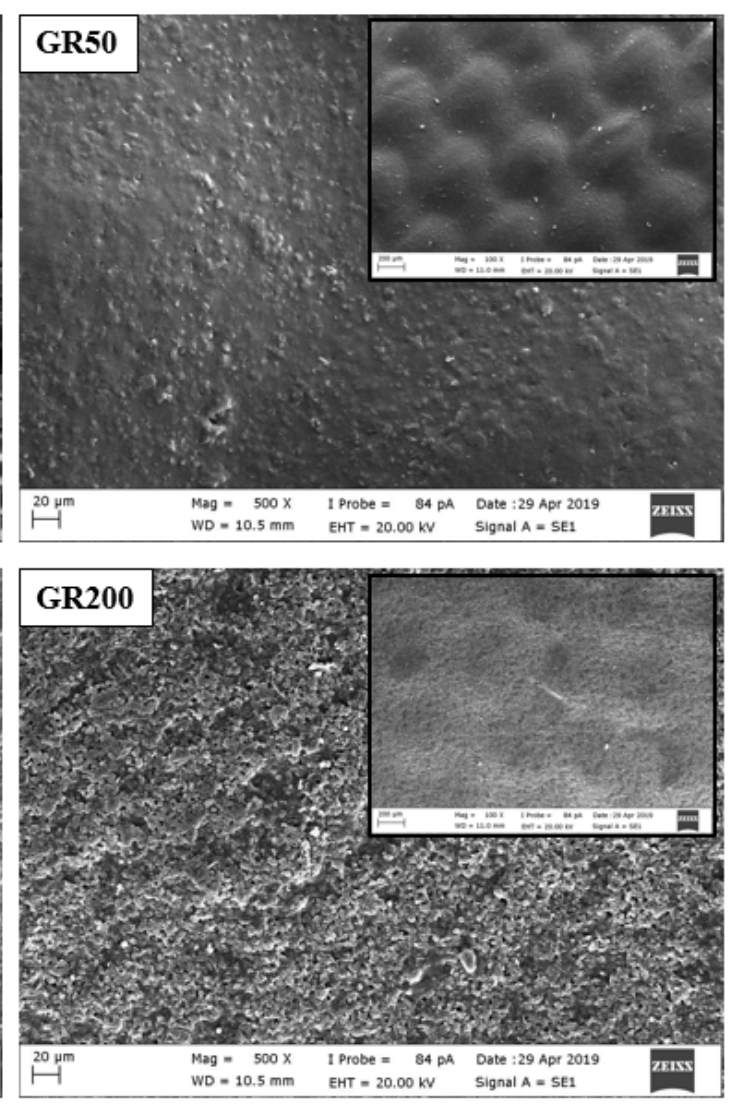

Fig. 2. SEM images of uncoated and coated fabrics (Mag $=100^{\mathrm{x}}$ and $500^{\mathrm{X}}$ ) 


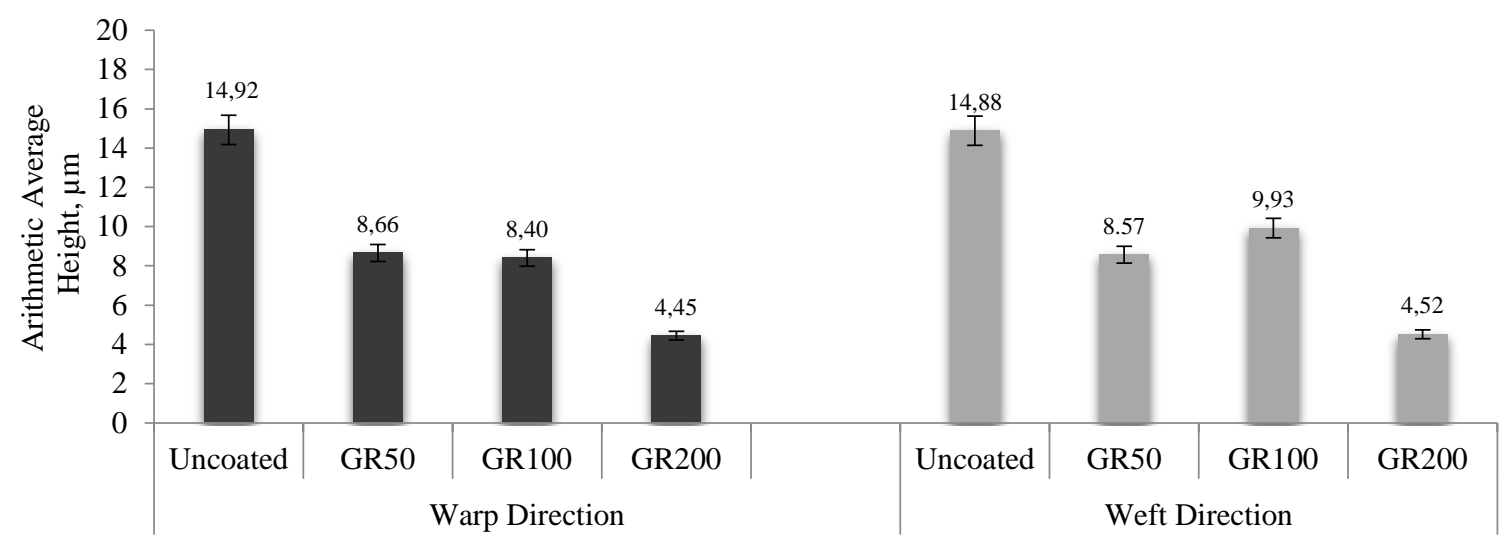

Fig. 3. Arithmetic average height values $\left(R_{\mathrm{a}}\right)$ of coated fabrics

In the study of Romdhani et al. [29], it was stated that the coating process increased the thickness of fabrics, surface characteristics changed and porosity decreased as similar to the results of the present study. However, in our study, the increasing coating concentration and mass per unit area caused alteration of Ra values in contrast to Ra results that did not change with the coating weight absorbed by fabric in Romdhani's study [29].

As shown in Fig. 3, the surface roughness values of the fabrics coated with $5 \%$ and $10 \%$ graphene were close to each other. With the coating process, the fabrics' surface roughness values decreased due to the filling of the gaps between the yarn crown and the gap regions, as seen in Fig. 2. The surface roughness significantly reduced at $20 \%$ concentration. In this concentration, there was slightly no difference in height between the peak and valley (gap) zones on the surface due to the nearly full filling of the gaps between the peak and valley regions.

Despite the increasing coating concentration, the decrease in the roughness value of the fabrics can also create an advantage in terms of the effectiveness of the functional properties. For example, it was stated that increasing surface roughness might negatively affect the conductivity results when high electrical conductivity was aimed [30].

The mean height of peaks and the mean depth of valleys values of uncoated and coated fabrics are given in Fig. 4 and Fig. 5. The base fabric used has a plain weave structure where the weft and warp threads intersect one to one. The yarns that have a one-to-one connection in the plain weave form peak and valley regions in the intersection areas. Fig. 4 and Fig. 5 show that these peaks and valleys (indentation

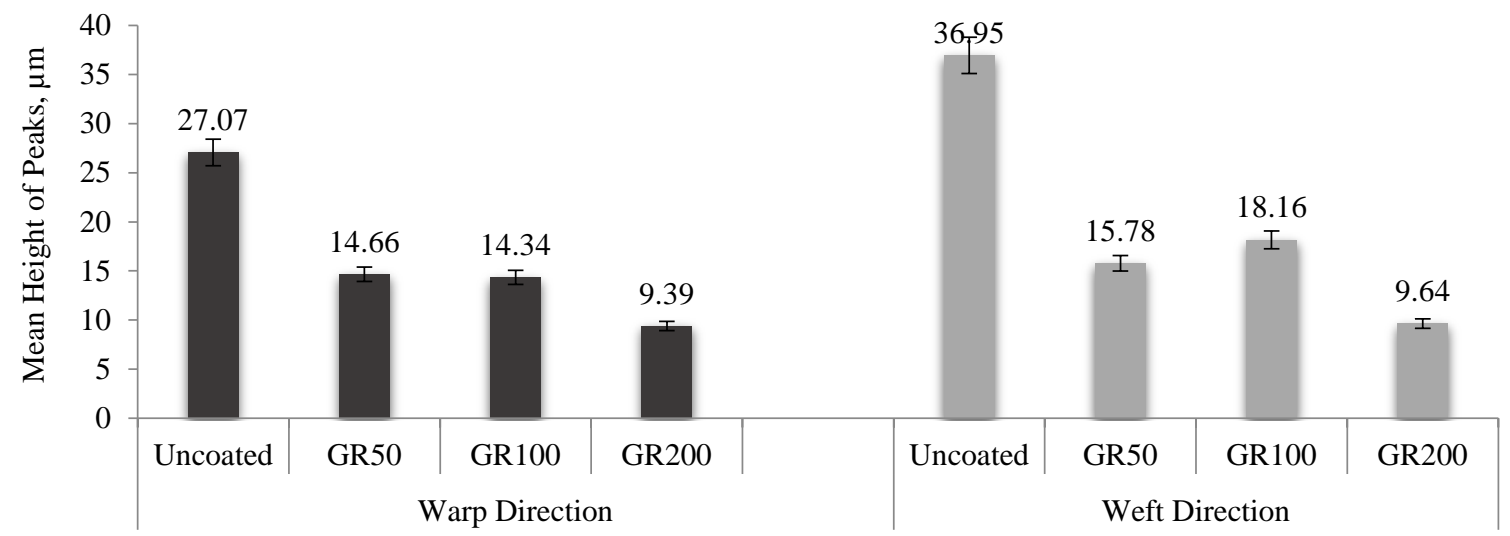

and protrusion regions) cause the high $R_{\mathrm{pm}}$ and $R_{\mathrm{vm}}$ values seen in the uncoated fabric.

It was seen that there was a significant decrease in the mean of the maximum height of peaks $\left(R_{\mathrm{pm}}\right)$ and mean of the maximum depth of valleys $\left(R_{\mathrm{vm}}\right)$ obtained for each sampling length of the assessment length after graphene coating. It was also observed that both weft and warp direction, $R_{\mathrm{pm}}$ and $R_{\mathrm{vm}}$ values of the coated surfaces were similar. This result indicated that the coating paste provided a very homogeneous penetration to the peaks and valleys on the fabric surface. Stable coating surfaces were obtained even at the highest filler (graphene) concentration.

When the fabrics coated with $5 \%$ and $10 \%$ graphene (GR50 and GR100) had close results, the lowest $R_{\mathrm{pm}}$ and $R_{\mathrm{vm}}$ values were obtained at $20 \%$ concentration (GR200) due to the filling rate of the gaps at the intersection points was higher in GR200.

Fig. 3 showed that the warp and weft directional $R_{\mathrm{a}}$ values of the fabrics were close to each other. It was considered that the skewness $\left(R_{\mathrm{sk}}\right)$ parameter could be used to distinguish between two surface profiles having the same $R_{\mathrm{a}}$ values but with different shapes [27]. Therefore, $R_{\mathrm{sk}}$ assessments were made before and after the coating process. When Fig. 6 was examined, it was seen that the skewness value $\left(R_{\mathrm{sk}}\right)$ was around zero going from -0.57 to 0.07 . It was thought that the high negative $R_{\text {sk }}$ values in the warp direction of uncoated fabric were due to the warp yarns' higher crimp values (Table 1) compared to weft yarns and the deep scratches in the warp direction, which arises from the high crimped structure of the warp yarns.

Fig. 4. Mean height of peaks values $\left(R_{\mathrm{pm}}\right)$ of fabrics 


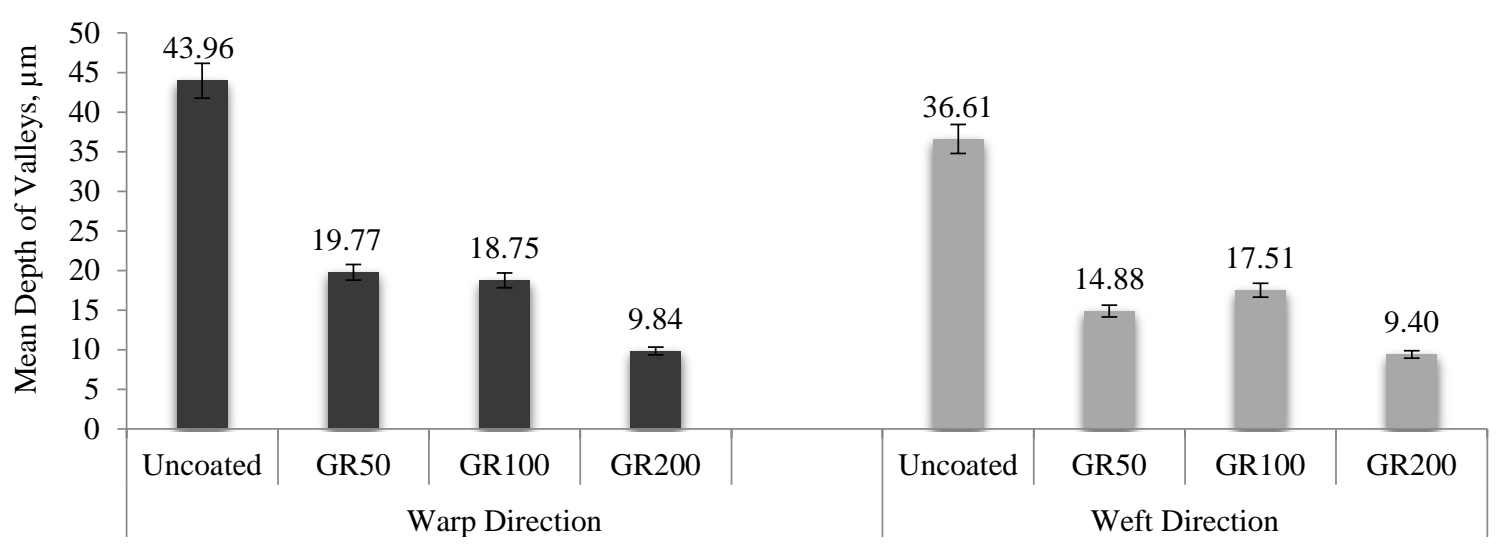

Fig. 5. Mean depth of valleys values $\left(R_{\mathrm{vm}}\right)$ of fabrics

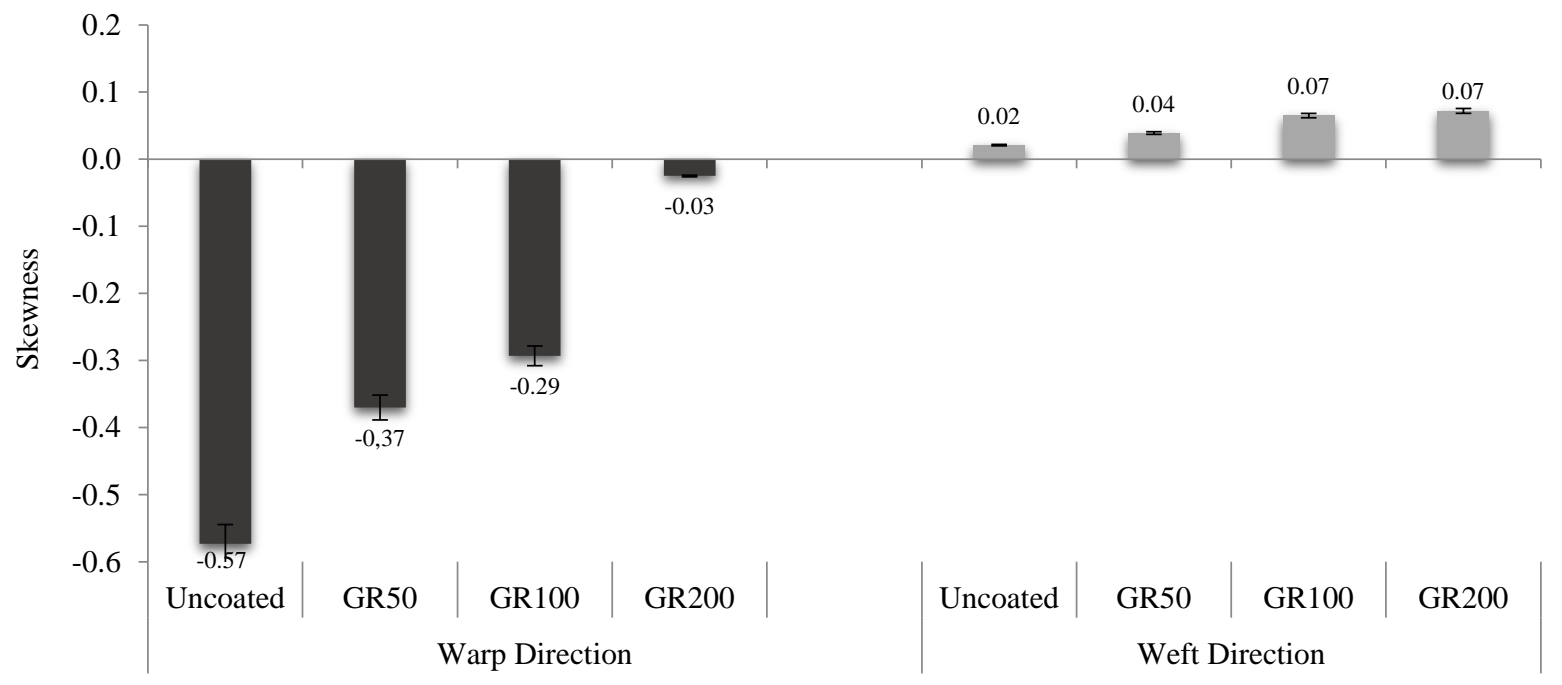

Fig. 6. Skewness $\left(R_{\mathrm{sk}}\right)$ values of fabrics

When the warp directional results of coated fabrics were investigated (Fig. 6), $R_{\text {sk }}$ values approached almost zero with increasing graphene concentration, especially at $20 \%$ rate. However, it was observed that the $R_{\text {sk }}$ values of coated fabrics in the weft direction were close to zero and they did not change significantly between each other.

It is known that negative skewness indicates a predominance of valleys [29]. It was observed that (Fig. 2) the peak and valley areas formed by the yarn intersections on the fabric surface were more prominent at $5 \%$ and $10 \%$ than $20 \%$ concentration. Hence, more symmetrical height distribution was observed in GR200 coded sample.

\subsection{Assessment of surface friction coefficient of coated fabrics}

The friction coefficients of the fabrics were investigated using a standard wool abrasive cloth. The changes in the friction coefficient (static and kinetic) values of fabrics are given in Fig. 7. As shown in the results, the increase in the graphene concentration reduces the friction coefficient of the fabric surfaces.

The uncoated fabric had the highest static and kinetic friction coefficient value. The friction coefficient values of GR50 and GR100 coded fabrics were close to each other and it decreased significantly at $20 \%$ concentration rate. Similarly, in the study of Berman et al. [23] the results indicate that graphene on the sliding surface was able to afford reasonably low friction coefficients. A possible explanation of this, graphene as a two-dimensional material, shears easily at the sliding contact interface and, hence, provides low friction. In another study, the friction coefficient of the silicon wafer was reduced by $1 / 6$ when using graphene oxide film [25].

When the friction coefficient values compared between the uncoated and coated fabrics, static and kinetic friction coefficient values decreased by nearly $6.69 \%$ and $3.45 \%$ for GR50, $9.66 \%$ and $16.13 \%$ for GR100, $40.17 \%$ and $42.11 \%$ for GR200, respectively.

Materials for use in tribological applications are expected to have low friction and high wear resistance properties [31]. Because graphene has a low friction coefficient [32], it is expected that the coated fabric will be affected to a minimum extent by the abrasion effect due to friction. The abrasion test results presented in our previous study, the weight loss in graphene-coated fabrics was at most $0.47 \%$ even after 100.000 cycles [9] and it was observed that they had high abrasion resistance. The surface friction coefficient values obtained in this study were consistent with abrasion results as expected. 


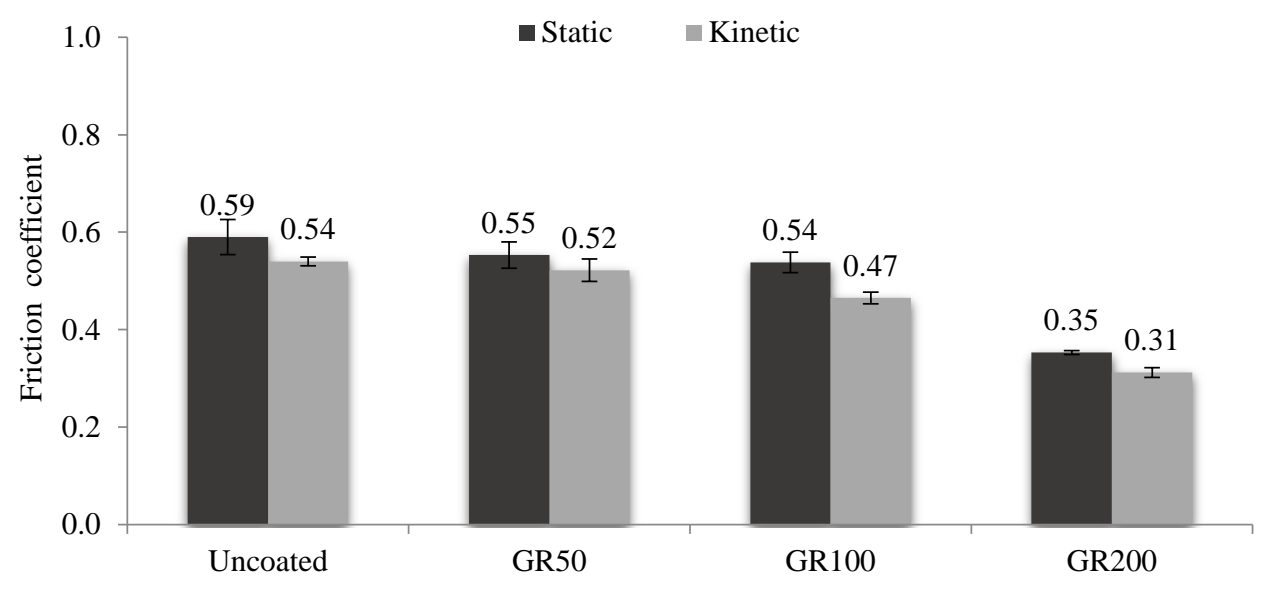

Fig. 7. Friction coefficient values of fabric

\section{CONCLUSIONS}

The surface properties of coated fabrics are essential parameters that effect the performance properties of the final product. In this study, as a new contribution to the literature, the effect of graphene coating on the roughness $\left(R_{\mathrm{a}}, R_{\mathrm{pm}}, R_{\mathrm{p}}, R_{\mathrm{vm}}, R_{\mathrm{v}}\right.$ and $\left.R_{\mathrm{sk}}\right)$ and friction (static, kinetic) properties of a textile material was examined for the first time. Experimental results showed that fabric surface roughness values decreased significantly, especially at $20 \%$ concentration. When the friction property between the standard wool abrasive fabric and the coated fabrics was investigated, the friction coefficient decreased with increasing concentration. Similarly, the lowest friction coefficient values were obtained at maximum graphene concentration.

As is known, the higher the coefficient of friction, the higher the abrasion. The abrasion that may occur on the surface of a coated fabric by interaction with other surfaces is a feature that must be considered. Therefore, it is important that the coated surface has a good performance after friction with other surfaces.

As the concentration increases, the decrease in surface roughness and friction coefficient values will be advantageous in cases where the concentration needs to be increased for the functional property of the fabrics. The decrease in roughness with the improvement in functional properties can be considered as an aesthetically positive result.

When the results presented in the study were evaluated together with our previous studies on graphene and other studies demonstrating the superior properties of graphene in the literature, it was considered that graphene was a potential filling material that could be used in areas such as anti-wear clothing and thin protective clothing in the textile coating besides its common usage areas.

\section{REFERENCES}

1. Akovali, G. Advances in Polymer Coated Textiles. Smithers Rapra, Shropshire, 2012: pp. 1-6.

2. Sen, A.K. Coated Textiles: Principles and Applications. Crc Press, Boca Raton, Florida, 2007: pp. 264.
3. Sahito, I.A., Sun, K.C., Arbab, A.A., Qadir, M.B., Jeong, S.H. Graphene Coated Cotton Fabrics as Textile Structured Counter Electrode for DSSC Electrochimica Acta 173 2015: pp. 164-171.

https://doi.org/10.1016/j.electacta.2015.05.035

4. Kongahge, D., Foroughi, J., Gambhir, S., Spinks, G.M., Wallace, G.G. Fabrication of a Graphene Coated Nonwoven Textile for Industrial Applications RSC Advances 6 (77) 2016: pp. 73203-73209. https://doi.org/10.1039/C6RA15190F

5. Celen, R., $\quad$ Manasoglu, G., $\quad$ Ulcay, Y., $\quad$ Kanik, $M$. Investigation of Performance Properties of Graphene Coated Fabrics International Journal of Modern Research in Engineering and Technology 3 (11) 2018: pp. 9-14.

6. Shateri-Khalilabad, M., Yazdanshenas, M.E. Fabricating Electroconductive Cotton Textiles Using Graphene Carbohydrate Polymers 96 (1) 2013: pp. 190-195. https://doi.org/10.1016/j.carbpol.2013.03.052

7. Tas, M., Altin, Y., Bedeloglu, A. Graphene and Graphene Oxide-Coated Polyamide Monofilament Yarns for FiberShaped Flexible Electrodes The Journal of The Textile Institute 110 (1) 2019: pp. 67-73. https://doi.org/10.1080/00405000.2018.1460039

8. Neves, A.I.S., Bointon, T.H., Melo, L.V., Russo, S., De Schrijver, I., Craciun, M.F., Alves, H. Transparent Conductive Graphene Textile Fibers Scientific Reports 5 (9866) 2015: pp. $1-7$.

9. Manasoglu, G., Celen, R., Kanik, M., Ulcay, Y. Electrical Resistivity and Thermal Conductivity Properties of GrapheneCoated Woven Fabrics Journal of Applied Polymer Science 136 (40) 2019: pp. 48024. https://doi.org/10.1002/app.48024

10. Sülar, V., Öner, E., Okur, A. Roughness and Frictional Properties of Cotton and Polyester Woven Fabrics Indian Journal of Fiber \& Textile Research 38 (4) 2013: pp. 349-356.

11. Wan, T., Stylios, G.K. Effects of Coating Process on the Surface Roughness of Coated Fabrics The Journal of the Textile Institute 108 (5) 2017: pp. 712 - 719.

12. Kalebek, N.A., Babaarslan, O. A Study of Abrasion and Frictional Behaviour of Nonwoven Interlining Produced with Different Coating Methods Fibers and Polymers 12 (3) 2011: pp. 371-375. https://doi.org/10.1007/s12221-011-0371-2 
13. Periyasamy, S., ASM, R., Patil, P.G. Submicron Surface Roughening of Aliphatic Polyamide 6, 6 Fabric through Low Temperature Plasma and Its Effect on Interfacial Bonding in Rubber Composite Journal of Industrial Textiles 47 (8) 2018: pp. 2029-2049. https://doi.org/10.1177/1528083717720202

14. Akgun, M. The Effect of Fabric Balance and Fabric Cover on Surface Roughness of Polyester Fabrics Fibers and Polymers 14 (8) 2013: pp. $1372-1377$. https://doi.org/10.1007/s12221-013-1372-0

15. Akgun, M. Assessment of the Surface Roughness of Cotton Fabrics Through Different Yarn and Fabric Structural Properties Fibers and Polymers 15 (2) 2014: pp. 405-413. https://doi.org/10.1007/s12221-014-0405-7

16. Akgun, M. Surface Roughness Properties of Polyester Woven Fabrics After Abrasion The Journal of The Textile Institute 105 (4) 2014: pp. 383-391. https://doi.org/10.1080/00405000.2013.813664

17. Akgun, M. Assessment of the Effect of Fabric Constructional Parameters on Surface Roughness of Wool Fabrics The Journal of The Textile Institute 106 (8) 2015: pp. 845-852. https://doi.org/10.1080/00405000.2014.948730

18. Akgun, M. Effect of Yarn Filament Fineness on the Surface Roughness of Polyester Woven Fabrics Journal of Engineered Fibers and Fabrics 10 (2) 2015: pp. 121-128. https://doi.org/10.1177/155892501501000214

19. Akgun, M. Surface Roughness Properties of Wool Woven Fabrics After Abrasion The Journal of The Textile Institute 107 (8) 2016: pp. 1056-1067. https://doi.org/10.1080/00405000.2015.1083352

20. Akgun, M., Becerir, B., Alpay, H.R. The Effect of Fabric Constructional Parameters on Percentage Reflectance and Surface Roughness of Polyester Fabrics Textile Research Journal 82 (7) 2012: pp. $700-707$. https://doi.org/10.1177/0040517511431292

21. Bertaux, E., Le Marec, E., Crespy, D., $\quad$ Rossi, R., Hegemann, D. Effects of Siloxane Plasma Coating on the Frictional Properties of Polyester and Polyamide Fabrics Surface and Coatings Technology $204(1-2)$ 2009: pp. $165-171$. https://doi.org/10.1016/j.surfcoat.2009.07.016

22. Mostafa, K., Ameen, H., Morsy, M., el-ebiassy, A., El-Sanabary, A., Adel, M., Salah, A. Production of HighPerformance Textiles via Pioneering Strengthening Approach
Using Starch Nanoparticles Journal of Industrial Textiles 50 (3) 2019: pp. $278-292$. https://doi.org/10.1177/1528083719827365

23. Berman, D., Erdemir, A., Sumant, A.V. Reduced Wear and Friction Enabled by Graphene Layers on Sliding Steel Surfaces in Dry Nitrogen Carbon 59 2013: pp. 167-175. https://doi.org/10.1016/j.carbon.2013.03.006

24. Pu, J., Wan, S., Zhao, W., Mo, Y., Zhang, X., Wang, L., Xue, Q. Preparation and Tribological Study of Functionalized Graphene-IL Nanocomposite Ultrathin Lubrication Films on Si Substrates The Journal of Physical Chemistry C 115 (27) 2011: pp. $13275-13284$. https://doi.org/10.1021/jp111804a

25. Liang, H., Bu, Y., Zhang, J., Cao, Z., Liang, A. Graphene Oxide Film as Solid Lubricant ACS Applied Materials \& Interfaces 5 (13) 2013: pp. 6369-6375. https://doi.org/10.1021/am401495y

26. Bhushan, B. Modern Tribology Handbook, two volume set. CRC Press, Boca Raton, Florida, 2000: pp. 1760.

27. Gadelmawla, E.S., Koura, M.M., Maksoud, T.M.A., Elewa, I.M., Soliman, H.H. Roughness Parameters Journal of Materials Processing Technology 123 (1) 2002: pp. $133-145$. https://doi.org/10.1016/S0924-0136(02)00060-2

28. Ajayi, J.O., Elder, H.M. Effects of Surface Geometry on Fabric Friction Journal of Testing and Evaluation 25 (2) 1997: pp. $182-188$. https://doi.org/10.1520/JTE11476J

29. Romdhani, Z., Hamdaoui, M., Baffoun, A., Maatoug, N., Roudesli, S. Surface Roughness Evaluation of Treated Woven Fabric by Using a Textile Surface Tester Research Journal of Textile and Apparel 17 (2) 2013: pp. 51-60. http://dx.doi.org/10.1108/RJTA-17-02-2013-B008

30. Lou, E.Z., Heun, S., Kennedy, M., Wollschläger, J., Henzler, M. Surface Roughness and Conductivity of Thin Ag Physical Review B 49 (7) 1994: pp. 4858-4865. https://doi.org/10.1103/PhysRevB.49.4858

31. Jones, M.H., Scott, D. Industrial Tribology: The Practical Aspects of Friction, Lubrication and Wear. Elsevier, North Holland, 1983: pp. 1-516.

32. Shin, Y.J., Stromberg, R., Nay, R., Huang, H., Wee, A.T., Yang, H., Bhatia, C.S. Frictional Characteristics of Exfoliated and Epitaxial Graphene Carbon 49 (12) 2011: pp. 4070-4073. https://doi.org/10.1016/j.carbon.2011.05.046 